\title{
¿Más allá de la justicia correctiva?: potencialidades de la restitución de tierras en la superación de los conflictos armados*
}

\author{
Gustavo Rojas-Páez* \\ Andrés-Mauricio Guzmán-Rincón"**
}

Recibido: agosto de 2015

Evaluado: octubre de 2015

Aprobado: noviembre de 2015

\section{RESUMEN}

La restitución de tierras, como instrumento de reparación en el contexto de la justicia transicional, cuenta con importantes herramientas para lograr una acción articulada con los objetivos de justicia social agraria, propios del derecho constitucional y del derecho internacional de los derechos humanos. Los retos que se derivan de su implementación en escenarios donde el conflicto ha sido originado en buena medida por las desigualdades sociales justifican esta articulación y evidencian su necesidad. La explicitación y la identificación analítica de estos puntos de encuentro son el objeto de este artículo; el referente teórico gira entorno a la potencialidad de la justicia correctiva en la contribución a la consecución de la justicia social o redistributiva.

Palabras clave: Restitución de tierras, justicia transicional, justicia correctiva, post-conflicto.

Artículo producto de investigación en el marco del proyecto "constitucionalismo global, justicia transicional y multiculturalismo" que adelantan los autores desde el mes de febrero de 2015 en la Facultad de Derecho de la Universidad Libre de Colombia.

* Abogado de la Universidad Libre, magíster en Sociología Jurídica del Centro Internacional de Sociología Jurídica de Oñati y candidato a Phd en la Universidad de Friburgo. Docente investigador de la Facultad de Derecho de la Universidad Libre de Colombia. Correo electrónico grojaspaez@yahoo.es

*** Abogado y magíster en Derecho de la Universidad Nacional de Colombia. Magíster en Derechos Humanos y Democratización de la Universidad Nacional de San Martín. Docente investigador de la Facultad de Derecho de la Universidad Libre de Colombia. Correo electrónico andresm.guzmanr@unilibrebog.edu.co 


\title{
Beyond the Corrective Justice? Possibilities to Land Restitution after Solving the Armed Conflicts
}

\begin{abstract}
Restitution of lands, as a reparation instrument within the context of transitional justice, has important tools for executing an action articulated to the agricultural social justice objectives included in the constitutional law and the international human rights law. Challenges resulting from the implementation of the restitution, in scenarios where armed conflict has been mainly caused by social inequality, justify this articulation and reflect the need for it. Explicitness and analytical identification of these meeting points comprise the main intention of this article. The theoretical reference turns around the possibility of having a corrective justice to achieve social and redistributive justice.
\end{abstract}

Key words: Land restitution; transitional justice; corrective justice; post-conflict. 


\section{INTRODUCCIÓN}

La persistencia de los conflictos armados implica la continua vulneración de los derechos humanos de las personas, entre ellos el de la privación arbitraria de la propiedad y la vivienda. En contextos específicos, varios estudios han establecido conexiones estrechas entre este fenómeno y la concentración de la propiedad rural en zonas en las que las élites políticas y económicas son muy poderosas como ha ocurrido en Colombia. A su vez, la concentración se asocia a la desigualdad social y esta última es considerada como una de las causas estructurales del conflicto. De acuerdo con lo anterior, la consecución de la paz implicaría no solo la búsqueda de la reparación integral a las víctimas mediante la restitución de las tierras despojadas o abandonadas, sino, además, la superación de la desigualdad social, lo que implica contrarrestar fenómenos como la concentración de la propiedad.

Esto nos lleva a pensar en la necesidad de esclarecer los puntos de articulación entre los programas de restitución de tierras a causa de la privación arbitraria de la propiedad y la vivienda en el marco del conflicto y, por otra parte, los objetivos de justicia social y redistributiva en el campo que surgen para contrarrestar las desigualdades sociales. En últimas este debate ha girado en torno al carácter complementario entre la justicia correctiva y la justicia redistributiva.

Lo anterior implica el abordaje de una temática bastante extensa y compleja; de allí que el presente artículo, que se entien- de como un primer acercamiento al tema, delimita su objeto al indagar en el concepto y la regulación jurídica internacional de la restitución de tierras, identificando sus peculiaridades, así como destacando aquellos elementos que, desde una perspectiva de los derechos humanos que los conciben como integrales e interdependientes, tienen la potencialidad de aproximarla, sin desnaturalizarla, al cumplimiento de objetivos de justicia social y redistributiva. Así las cosas, la pregunta que orienta esta disertación se expresa de la siguiente manera: ¿Cuáles son los componentes normativos de la restitución de tierras desde el derecho internacional que justifican la adopción de un concepto orientado también a la consecución de objetivos de justicia social o redistributiva, o al menos que permitan su articulación con objetivos de política social?

En el caso colombiano esta pregunta resulta de la mayor pertinencia por el hecho de que en el momento actual es posible la transición hacia la paz tras el avance significativo de las negociaciones de paz entre la guerrilla de las FARC y el Gobierno Nacional, lo que implica la inminente reflexión en torno al diseño y ejecución de políticas encaminadas a la reconciliación del país y a solucionar de forma definitiva las condiciones que originaron el conflicto. En este escenario resulta ineludible el diálogo sobre la debida articulación entre las políticas de justicia transicional y las que promueven la justicia social.

El planteamiento que defendemos es que del análisis efectuado al menos 
existen tres componentes del corpus jurídico internacional que desarrollan y conciben la restitución de tierras desde una perspectiva integradora en la que se trazan puentes entre la justicia social y la correctiva. En primer lugar, y desde la interpretación autorizada de los denominados Principios Phineiro, la restitución de tierras se entiende ante todo como un mecanismo que aporta de forma significativa al logro de una paz sostenible a partir de la promoción del desarrollo social y económico, que persigue como fin último la consecución de soluciones duraderas que permitan a las víctimas superar la pobreza y la dependencia. En segundo lugar, se entiende la restitución de tierras como mecanismo de la justicia transicional, que debe estar orientada hacia la consecución de la reconciliación, lo que implica entre otros aspectos que esta debe contribuir a evitar la división social y la conflictividad a partir del fortalecimiento de la democracia; así, por ejemplo, en dichos principios se incorpora una serie de medidas encaminadas a garantizar el acceso a la vivienda y a tierras, a los ocupantes secundarios en situación desfavorable en los programas de restitución. En tercer lugar, la consagración explícita en las directrices voluntarias sobre la gobernanza de la tenencia de la tierra, de prescripciones que contemplan que la consecución de objetivos como la erradicación del hambre y la pobreza, y el logro de medios de vida sostenibles, así como el desarrollo rural, se encuentran estrechamente ligados a la efectividad de las medidas de reparación integral y específicamente a la restitución de tierras. Estos elementos normativos deben ser entendidos en el contexto de las directrices hermenéuticas del derecho internacional que prescribe su comprensión integral a partir de la afirmación de interdependencia e integralidad de los derechos humanos.

El texto se divide en cuatro partes: en la primera, se efectúa un breve análisis teórico de los puntos de encuentro entre la justicia social y la justicia correctiva que sirve para comprender sus proximidades. En la segunda, se indaga por la importancia de la reflexión constitucional en el entendimiento de los mecanismos de la justicia transicional, para observar en qué medida aspectos como su flexibilidad y exigencia de adecuación a las necesidades y realidades históricas, así como la incorporación de elementos de ponderación, permiten en buena medida su ajuste con la consecución de objetivos de política social. En la tercera, se caracterizan las obligaciones y medidas que surgen de la restitución de tierras, entendida como componente de la reparación integral en el derecho internacional, haciendo hincapié en sus elementos articuladores con la política social, al menos los más relevantes, mientras que en la parte final se muestra cómo la regulación de la propiedad rural desde la perspectiva de los derechos humanos ha reconocido la importancia de integrar sus objetivos estratégicos con elementos que conllevan la reparación integral en contextos de conflicto, lo que es posible identificar claramente en las directrices voluntarias sobre la gobernanza responsable de la tenencia de la tierra, proferidas por Naciones Unidas recientemente. 
La presente estructura permite comprender el derrotero metodológico del artículo el cual analiza y sintetiza algunas posturas teóricas sobre el tema para posteriormente identificar medidas, directrices y orientaciones conceptuales en instrumentos internacionales que en últimas permiten constatar la existencia de una articulación desde una perspectiva normativa. El derrotero interpretativo y la potencialidad de la comprensión de esta articulación tienen como contexto interpretativo la justicia transicional; por tal razón previamente se describe su ámbito y alcance en esta discusión.

\section{POSTURAS ARTICULADORAS ENTRE LA JUSTICIA REDISTRIBUTIVA Y LA CORRECTIVA}

Significativas reflexiones teóricas han puesto de manifiesto la necesidad de armonizar la justicia distributiva con la justicia correctiva; sin embargo, existen algunas diferencias sobre lo que esto significa. Por ejemplo, Elster (2012) sostiene que la reforma agraria en el posconflicto está llamada a cumplir con los fines de ambos modelos de justicia, mientras que por ejemplo Kalmanovitz (2010) sostiene que en algunos contextos en los que han existido conflictos de alta intensidad donde la mayoría de la población se encuentra empobrecida, debe prevalecer la búsqueda de la justicia redistributiva sobre la justicia restaurativa, en tanto que Uprimny-Yepes y Sánchez (2010) plantean las ventajas de instaurar un concepto de restitución de tierras amplio y con carácter transformador, que permita al Estado cumplir con los objetivos de la justicia correctiva pero contribuyendo al mismo tiempo a lograr las transformaciones sociales necesarias para superar las causas estructurales del conflicto. Por tal razón en los apartados siguientes, se efectúa un análisis sucinto de estos planteamientos, identificando sus principales aportes a la comprensión del tema.

\subsection{Reflexiones sobre la reforma agraria}

Las experiencias históricas demuestran que la justicia transicional tiene potencialidad para lograr la superación de injusticias sociales y promover transformaciones democráticas, ya que, por lo general, estas han culminado en reformas constitucionales y han ayudado a impulsar medidas para aliviar la pobreza, distribuir la riqueza, y sentar las bases del crecimiento económico (Bergsmo, 2012).

Sin embargo, también es cierto que existen tensiones entre la justicia redistributiva, las reparaciones después del conflicto y la eficiencia económica, en la medida en que las dos últimas dependen, en parte, de un buen desempeño de la economía; además, cada una tiene prioridades distintas, por ejemplo, desde la perspectiva de la eficiencia económica, la asignación de las tierras principalmente debe efectuarse a quien tenga la mejor capacidad para explotarlas, en tanto que desde la perspectiva de la reparación, esta debe corresponder a las víctimas que en el marco del conflicto fueron privadas de sus tierras. Frente a estas tensiones, es importante lograr la armonización de estos intereses contrapuestos. Precisamente en 
las experiencias transicionales se encuentran aspectos relevantes que evidencian esfuerzos por lograr esta armonización (Bergsmo, 2012).

Luego de hacer una tipología de las guerras civiles, Elster (2012) sostiene que en aquellas que se ocasionan principalmente por injusticias económicas, el logro de una paz estable solo es posible si se corrigen las injusticias que se generaron en la guerra, así como aquellas que la originaron, mediante la justicia transicional y la justicia redistributiva, respectivamente. Posteriormente muestra la forma en que la reforma agraria puede servir a ambos fines, haciendo énfasis en las medidas de redistribución de la tierra, y deja en evidencia que lo anterior puede ir de la mano con la justicia transicional. En esta vía, la articulación entre ambos modelos de justicia implica medidas de doble propósito que, en lo posible, eviten la competencia entre sujetos por un recurso escaso como la tierra, en este caso, las personas empobrecidas y las víctimas del conflicto.

Para tal fin plantea un concepto amplio de justicia que tiene en cuenta la eficiencia de las medidas a implementar. En tal sentido, sostiene que existen buenas razones para afirmar que la producción agrícola en pequeñas propiedades rurales es más eficiente y en esa medida la redistribución de la tierra conllevaría un crecimiento económico que permitiría fortalecer las medidas de reparación, sin que esto implique concebir que la justicia restaurativa tenga una prioridad absoluta.
Del conjunto de tierras disponibles, algunas se podrían asignar a las víctimas inmediatas de la violencia y a otras a quienes se podría denominar víctimas accidentales conexas. Por último, se podrían asignar algunos recursos a personas que no son víctimas de la guerra ni directa ni accidentalmente, sino que simplemente necesitan tierras para tener una vida digna (Elster, 2012, p. 23).

Así las cosas, la solución intermedia pone de manifiesto la necesidad de lograr la adopción de medidas encaminadas a lograr ese "doble propósito", como por ejemplo establecer un límite a las hectáreas a restituir y garantizar el acceso a la tierra no solo de las víctimas sino también de quienes sean vulnerables.

\subsection{El concepto de restitución de tierras con enfoque transformador}

Por otra parte, aunque reflexionando sobre las medidas que permitan lograr esas medidas de "doble propósito" pero desde un análisis de la restitución de tierras, Uprimny-Yepes y Sánchez (2010) plantean que se justifica la concepción de una restitución "gruesa", bajo la cual se propende por una política que contribuya a la redistribución de la propiedad de la tierra y al reconocimiento de los derechos de las víctimas; de igual forma, su aproximación es más sensible hacia la economía campesina y la participación de esta población en la economía nacional. De allí que desde esta perspectiva se persigue no solo la justicia correctiva sino la redistribución y el reconocimiento de la propiedad en favor de los campesinos y de las comunidades étnicas. 
De acuerdo con estos autores, algunas ideas sobre las características específicas de esta perspectiva que permitirían maximizar su potencial transformador serían: la limitación del número de hectáreas a ser restituidas; el establecimiento de sistemas de priorización en favor de grupos socialmente discriminados en relación con la propiedad de la tierra; la restitución de títulos a nombre de mujeres y hombres equitativamente; la creación de un procedimiento participativo que tienda a la reconstrucción de territorios y de las relaciones sociales del campesinado; y otras que propendan por la democratización de la propiedad de la tierra como el establecimiento de una bolsa de tierras que se fortalezca con predios procedentes de políticas que incentiven la desconcentración de la propiedad.

\section{LA JUSTICIA TRANSICIONAL, LA JUSTICIA CORRECTIVA Y LA JUSTICIA SOCIAL}

En el apartado inmediatamente anterior, se identificaron posibles acciones o medidas que pueden contribuir a que los mecanismos de justicia correctiva, específicamente la restitución de tierras y viviendas a las víctimas del conflicto, se articulen con objetivos que van más allá, al encaminarse al logro de justicia social en contextos en los que los conflictos se originaron por desigualdades sociales y económicas. Las reflexiones sobre este asunto involucran de forma principal el estudio específico de ciertas experiencias históricas en los que se ha intentado hacer coincidir estos objetivos.
El presupuesto del que parten estas posturas es precisamente el de entender que la justicia transicional es el marco conceptual que posibilita este tipo de medidas dependiendo de las particularidades y el contexto de cada experiencia histórica. Por tal razón, a continuación se indaga sobre los elementos más característicos de este concepto, en especial sobre el margen de flexibilidad que permite para el logro de sus objetivos de reconciliación y paz, así como la garantía del mayor nivel posible de derechos de las víctimas. Indagamos en las líneas siguientes entonces si dentro de los objetivos de paz y reconciliación de la justicia transicional, se contempla y ampara la conexión con objetivos de redistribución de la tierra o de justicia social.

\subsection{El modelo de las transiciones democráticas}

En las sociedades que sufrieron transiciones democráticas luego de la superación de regímenes represivos como ocurrió en América Latina desde la década de los ochenta, la reflexión constitucional giró principalmente en torno a la consolidación de una nueva estructura institucional que garantizara su no repetición y posteriormente a priorizar arreglos institucionales adecuados para enfrentar la agenda de los crímenes del pasado. En ambos procesos las instituciones constitucionales asumen un papel fundamental e irreemplazable para adelantar los objetivos de la transición. De esta forma, la viabilidad y pertinencia de mecanismos excepcionales dependerá en buena parte del margen de maniobra constitucional que tengan (Sánchez E Ibáñez, 2014). 
En este contexto la justicia transicional se ha entendido como:

Un sistema o tipo de justicia de características particulares, que aspira a superar una situación de conflicto o postconflicto, haciendo efectivos en el mayor nivel posible, los derechos a la verdad, la justicia y la reparación de las víctimas frente a un pasado de graves y sistemáticas violaciones de los derechos humanos, teniendo como límite la medida de lo que resulte conducente al logro y mantenimiento de la paz social (Corte Constitucional de Colombia, Sentencia C-370 de 2006, 2006).

En consonancia con este concepto se entiende que esta se compone: "Por un conjunto de procesos de transformación social y política profunda en los cuales es necesario utilizar gran variedad de mecanismos para resolver los problemas derivados de un pasado de abusos a gran escala, a fin de lograr (...) servir a la justicia y lograr la reconciliación (...)" (Corte Constitucional de Colombia, Sentencia C-579 de 2013, 2013).

Esta definición incorpora elementos planteados por diferentes expertos en la materia, así como la concepción que al respecto adopta el Consejo de Seguridad de Naciones Unidas. En este punto, se referencian las Sentencias de la Corte Constitucional colombiana debido a que este alto tribunal ha tenido un rol protagónico en la definición del sentido y alcance de la justicia transicional a través de su jurisprudencia, logrando en muchos de sus fallos efectuar ponderaciones para conciliar las tensiones que se suscitan entre los objetivos del logro de la paz y la reconciliación, y, por otra parte, los derechos de las víctimas.

Esta ha entendido que la justicia transicional, atendiendo a su carácter especial, debe aplicarse solo a situaciones de excepción, y contempla cuatro elementos estructurales: i) sus medidas deben respetar un mínimo de justicia, que ii) se encuentra definido por el derecho internacional, especialmente por los derechos de las víctimas, iii) que se trata de la aplicación de justicia en situaciones estructuralmente complejas con particularidades específicas y por ello se admite la flexibilidad de estos estándares, y iv) que para su aplicación debe existir de manera cierta una situación cercana a la transición política (Sánchez \& Ibáñez, 2014).

\subsection{Tensiones inherentes a la justicia transicional y fórmulas de solución}

De acuerdo con la definición inicial de la justicia transicional, es posible inferir que esta pretende solucionar las tensiones que se suscitan entre la justicia y la paz, específicamente frente a la realización de los derechos de las víctimas reconocidos por el ordenamiento jurídico, y por otra parte, la necesidad de lograr superar el conflicto armado. La fórmula de solución implica lograr un equilibrio entre estos dos propósitos. Para ello, se plantea que "es necesario conseguir un delicado balance entre ponerle fin a las hostilidades y prevenir la vuelta a la violencia (paz negativa) y consolidar la paz mediante reformas estructurales y políticas incluyentes (paz positiva) (Corte 
Constitucional de Colombia, Sentencia C-579 de 2013, 2013).

Lo anterior es posible a partir de la consecución de cuatro objetivos: i) el reconocimiento de los derechos de las víctimas, específicamente sus derechos a la verdad, a la justicia y a la reparación integral; ii) el restablecimiento de la confianza pública a partir de la reafirmación de la relevancia de las normas que los perpetradores violaron, especialmente la inclusión en los acuerdos de paz de disposiciones que expresamente respalden el respeto al Estado de derecho; iii) la reconciliación, que implica esfuerzos para evitar la división social, recuperar un nivel de confianza y solidaridad que fomente una cultura democrática que les permita a las personas superar las experiencias de la violencia para que se sientan capaces de convivir con otros, y iv) el fortalecimiento de la democracia, mediante una participación plural que promueva la inclusión de todos los ciudadanos en las instituciones políticas.

Sin embargo, la tarea de lograr una adecuada proporción entre justicia y la obtención y preservación de la paz en el contexto de una transición es un asunto complejo, razón por la cual, "solo las circunstancias de cada caso concreto y las relaciones de poder que existen en una sociedad en un momento histórico dado podrán determinar si se debe renunciar a la justicia, a cuánto de justicia y bajo qué condiciones para conservar la paz" (Corte Constitucional de Colombia, Sentencia C-579 de 2013, 2013). Es decir, el tipo de mecanismos transicionales y su alcance dependerán, en buena medida, de las necesidades y circunstancias de cada experiencia histórica.

Frente a estos desafíos, la Corte Constitucional colombiana, tomando en cuenta los lineamientos internacionales sobre la materia, ha precisado los principios que deben ser empleados para resolver estas aporías:

El primero de ellos es el de la flexibilidad en la aplicación de ciertos estándares de implementación de justicia. El segundo hace referencia al reconocimiento de una amplia configuración por parte del legislador en el diseño de mecanismos de transición, aunque con límites establecidos en la constitución. El tercero es precisamente la sujeción a esos límites básicos, mientras que el cuarto es el de la aplicación del método de ponderación por parte de las autoridades judiciales para resolver las tensiones inherentes a la implementación de mecanismos de transición (Sánchez \& Ibáñez, 2014).

El método de ponderación busca que el juez haga respetar los límites constitucionales establecidos para estos mecanismos de justicia transicional sin sacrificar ninguno de los principios constitucionales que entran en tensión.

\section{LA RESTITUCIÓN COMO COMPONENTE FUNDAMENTAL DE LA REPARACIÓN INTEGRAL EN EL CONTEXTO DE LA JUSTICIA TRANSICIONAL}

Estos parámetros de racionalidad para comprender los límites y el alcance de la 
justicia transicional resultan útiles para comprender la restitución de tierras y reflexionar sobre su articulación con políticas de justicia social o redistributiva, advirtiendo que la definición de las medidas y acciones deberá efectuarse atendiendo al contexto de cada experiencia. Para tal fin, y en consonancia con este concepto, resulta clave identificar algunos elementos adicionales desde el derecho internacional de los derechos humanos que definen el horizonte conceptual y práctico de la restitución de tierras partiendo del concepto de reparación integral.

\subsection{Del carácter preferente a la restitución como componente de la reparación integral}

La aparición de programas de restitución se ha dado en el marco de los esfuerzos de la justicia transicional luego de graves violaciones a los derechos humanos. La restitución de tierras es uno de los mecanismos que mayor relación tiene con el concepto de reparaciones, debido a que mantiene orígenes históricos comunes y, en un principio, busca al igual que esta restituir a las víctimas a la condición de la que disfrutarían si no se hubiese dado la violación de sus derechos.

El derecho a la reparación surge en un momento histórico particular en el que el individuo se convierte en sujeto del derecho internacional, y bajo esta orientación, se profieren instrumentos jurídicos que dan lugar a instituciones que tienen por objeto establecer mecanismos de protección a los derechos humanos. En este contexto las obligaciones que surgen para los Estados de respetar y garantizar los derechos humanos, así como la consagración expresa del derecho de las víctimas a un recurso judicial efectivo, van a ser de una gran importancia (Williams, 2008).

Paulatinamente, el acceso a los sistemas jurídicos nacionales e internacionales por parte de los individuos se define como la posibilidad concreta de todas las personas, sin ninguna distinción, a obtener el restablecimiento de sus derechos a través de los medios dispuestos por la Administración de Justicia, los cuales deben ser efectivos, adecuados, oportunos, sencillos y serios.

Este derecho también se incluye en el Pacto Internacional de Derechos Civiles y Políticos de 1966 (artículos 2 y 3) e instrumentos regionales como la Convención Americana sobre Derechos Humanos (artículo 25). Incluso, a pesar de que el Pacto Internacional de Derechos Económicos, Sociales y Culturales (PIDESC) no incluye de forma expresa el derecho a un recurso efectivo, el Comité de las Naciones Unidas sobre Derechos Económicos, Sociales y Culturales (CDESC) ha sostenido que materializar estos derechos a través de todos los medios apropiados implica esta obligación.

En desarrollo de estos principios, después de la Segunda Guerra Mundial, la restitución pasó de ser la forma preferente de reparación fundada en el principio de justicia correctiva, a ser considerada como uno de los tipos de reparación que debían proveer los Estados a las víctimas individuales cuando fuesen responsables de violaciones a los derechos humanos. 
Este cambio en la comprensión de la restitución se corrobora con la adopción de los principios y orientaciones sobre el derecho a un recurso efectivo y a la reparación de las víctimas de graves violaciones del derecho internacional de los derechos humanos y graves violaciones del derecho internacional humanitario (Principios de Reparación de las Naciones Unidas) de la Asamblea General de las Naciones Unidas). En dicho instrumento también se amplía el alcance de la restitución al incorporar no solo bienes materiales recuperables sino también "la restauración de la libertad, el goce de los derechos humanos, identidad, vida familiar y ciudadanía, regreso al lugar de residencia, recuperación del empleo" tal y como lo dispone el párrafo 19. A la luz de este instrumento se considera que la pertinencia de las medidas adoptadas para reparar es mejor evaluada caso a caso y en esa medida resulta más adecuado no establecer una jerarquía a priori de las mismas (Williams, 2008).

En ese sentido como lo anota el relator especial de Naciones Unidas, Paulo Sergio Pinheiro, la restitución implica:

La devolución al propietario original o titular del derecho de toda vivienda o bien incautado arbitraria o ilegalmente [...] ese derecho debe reconocerse también como un elemento de los objetivos más amplios de consolidación de la paz y solución de situaciones posteriores a los conflictos, esencialmente también para la búsqueda de soluciones duraderas a las situaciones de desplazamiento y conflicto (Pinheiro, 2003, p. 6).
Este aspecto denota la importancia de la restitución como un componente más de la reparación en sociedades en transición que tiene como horizonte la búsqueda de soluciones duraderas frente al conflicto.

Al finalizar la Guerra Fría, la restitución de la propiedad se considera ahora en un sentido más estricto como la reparación preferente en favor de las víctimas de desplazamiento forzado en contextos de conflicto, lo cual se refleja en la aprobación, por parte de la Subcomisión de Derechos Humanos de las Naciones Unidas, de los Principios sobre vivienda y restitución de propiedad para los refugiados y desplazados (Principios de Restitución de las Naciones Unidas, o conocidos como Principios Phineiro). Este concepto, más delimitado, opera en situaciones de infracciones al derecho internacional humanitario que tienen como resultado bienes materiales recuperables, en especial frente a conflictos armados internacionales o nacionales, de violaciones graves de derechos humanos, de proyectos de desarrollo, de desalojos forzosos, así como de catástrofes naturales o causadas por el hombre. De esta forma la restitución logra preeminencia como respuesta integral frente a las violaciones a los derechos humanos (Williams, 2008).

Es así como, el derecho a un recurso judicial efectivo se concreta en la obligación del Estado de proveer un mecanismo para que las víctimas que hayan sido privadas de estos bienes tengan la posibilidad de exigir que los actos que los originaron sean remediados y obtener una reparación. En este contexto la restitución como 
medida preferente cobra sentido como una forma para evitar aceptar o legalizar cualquier adquisición arbitraria o ilegal por violaciones de derechos humanos, proyectos de desarrollo, o catástrofes, respecto de los hogares y las tierras de las que son titulares los refugiados y personas desplazadas (Proyecto Protección de tierras y patrimonio de la población desplazada, 2008).

El concepto de restitución ha sufrido algunos cambios importantes suscitados por la existencia de experiencias históricas concretas que han dinamizado la reflexión en torno a su contenido y alcance. Sin embargo, de forma específica este último instrumento internacional sigue teniendo una centralidad indiscutible para su comprensión; por eso en el apartado siguiente se identifican sus aspectos centrales, aunque haciendo énfasis en las características que refuerzan su relación con otras normas de derechos humanos y en aquellos elementos en los que sea posible identificar conexiones con objetivos de justicia social.

\subsection{Los principios sobre vivienda y restitución de propiedad para los refugiados y desplazados frente a la justicia social}

Como lo establece el principio 1 de este instrumento, los derechos a la restitución que se enuncian abarcan a todos los refugiados y personas desplazadas quienes hayan sido privadas de forma arbitraria o ilegal de sus hogares, tierras, bienes o lugares de residencia habitual, "independientemente de la naturaleza del desplazamiento o de las circunstancias que lo originaron", con lo cual se reconoce este derecho como una preocupación fundamental de los Estados y de la comunidad internacional como un elemento imprescindible en la consecución de una paz duradera y de un desarrollo sostenible (Organización de las Naciones Unidas, 2007).

En esa medida se considera que la restitución en últimas debe propender por constituirse en un aporte significativo en el logro de una paz sostenible que promueva el desarrollo social y económico. La restitución permite la integración de reflexiones sobre desarrollo, humanitarias y de emergencia en un marco en el que se reconocen derechos, se asegura la justicia y se promueven soluciones sostenibles de largo plazo. La restitución se ve como algo indispensable para promover la reconciliación, la reconstrucción y el desarrollo económico de la sociedad afectada (Proyecto Protección de tierras y patrimonio de la población desplazada, 2008).

Naciones Unidas también ha reconocido la importancia de la restitución en la consecución de soluciones duraderas que permitan a las víctimas superar la pobreza y la dependencia como consecuencia de los hechos victimizantes, lo que de alguna manera propicia que, en últimas, se establezca una relación con los objetivos de política social:

\footnotetext{
La restitución como recurso jurídico es un requisito fundamental para garantizar la sostenibilidad de prácticamente todas las soluciones duraderas
} 
posibles, no solo del retorno, ya que a menudo constituye el primer paso hacia la recuperación de una cierta autonomía por parte de aquellos sumidos en la pobreza y la dependencia a raíz del desplazamiento arbitrario de sus hogares (Organización de las Naciones Unidas, 2007, p. 20).

Por otra parte, y como lo establece el Principio 10 de los Principios Phineiro, los refugiados y desplazados tendrán derecho a no ser obligados ni coaccionados a regresar a sus anteriores hogares, tierras o lugares de residencia habitual. Pero si desean hacerlo deben tener acceso de forma efectiva a soluciones duraderas al desplazamiento distintas del regreso, y que satisfagan otros aspectos distintos a la restitución de sus viviendas, tierras y patrimonio.

De nuevo esta formulación sobre el derecho al retorno contempla una serie de prerrogativas que involucran la identificación de medidas para la consecución de condiciones de seguridad y dignidad, y de alternativas económicas y sociales que permitan el logro de soluciones duraderas para que se cumpla de forma efectiva con el derecho a la restitución.

\subsection{La restitución de tierras, vivienda y patrimonio frente a la ocupación secundaria}

Otro de los temas centrales que se desarrollan en los Principios Phineiro es el de la problemática de la ocupación secundaria; esta se configura en los eventos en que la propiedad, que es reclamada por parte de las víctimas que fueron privadas de ella, se encuentra ocupada por otras personas, lo que conlleva, en los programas de restitución, al retiro de estas últimas con el fin de devolverle el predio al reclamante exitoso y de esta forma garantizar de forma efectiva la restitución material y el goce de derechos.

Precisamente, la comunidad internacional, consciente de la necesidad de atender posibles situaciones de conflictividad social que se pueden ocasionar entre víctimas favorecidas por los programas de restitución y terceros vulnerables, ha establecido algunos derechos en favor de estos últimos, a la vez que promueve acciones por parte de los Estados, encaminadas a la restitución efectiva a través de medidas proporcionadas y razonables que respeten la dignidad de los terceros, favoreciendo escenarios de reconciliación y en consonancia con los objetivos de lograr una paz duradera y sostenible.

Estas obligaciones se recogen, entre otros, en el principio 17.3 que señala que los Estados deben adoptar medidas positivas para proteger a aquellos que no dispongan de medios para acceder a otra vivienda adecuada cuando deben abandonar la que ocupan en ese momento, así como esforzarse por encontrar y proporcionar viviendas o tierras alternativas a dichos ocupantes, incluso de forma temporal.

Haciendo una interpretación de este principio, el Manual sobre la restitución de las viviendas y el patrimonio de refugiados y personas desplazadas (Oficina del Alto Comisionado para los Derechos Humanos, 2007) plantea que este insta a los Estados 
a proteger a los segundos ocupantes frente a la indigencia y desalojo injustificados, al igual que de las situaciones que puedan afectar sus derechos humanos, recomendando desarrollar mecanismos para garantizar el acceso a otra vivienda a todos aquellos que se vieran obligados por ley a abandonar la vivienda que ocupan, por no ser sus titulares (p. 79).

En este contexto, los Estados deben brindar alternativas a los segundos ocupantes, y proporcionarles atención prioritaria a quienes se encuentren en una situación desfavorable. Por tal razón, el Consejo Económico y Social de Naciones Unidas, a través de las observaciones generales N. ${ }^{\circ} 4$ y 7 , en referencia a los desalojos forzosos ha establecido que es deber de los Estados garantizar en condiciones de igualdad, los derechos a la vivienda y el disfrute de los derechos económicos, sociales y culturales:

\begin{abstract}
Los Estados Partes reconocen el derecho de toda persona a un nivel de vida adecuado para sí y su familia, incluso alimentación, vestido y vivienda adecuados, y a una mejora continua de las condiciones de existencia (...) deben otorgar la debida prioridad a los grupos sociales que viven en condiciones desfavorables concediéndoles una atención especial (Oficina del Alto Comisionado de las Naciones Unidas para los Derechos Humanos, 1991).
\end{abstract}

Estos instrumentos internacionales prohíben al Estado incurrir en desalojos forzosos. Lo anterior se entiende como el hecho de hacer salir a personas, familias y/o comunidades de los hogares y/o las tierras que ocupan, en forma permanente o provisional, sin ofrecerles medios apropiados de protección legal o de otra índole ni permitirles su acceso a ellos. Cuando haya lugar a los desalojos, estos deben ceñirse de forma estricta a la ley y efectuarse de conformidad con las disposiciones de los Pactos Internacionales de Derechos Humanos.

Correlativo a este deber, coexiste el derecho de las personas a no ser desalojadas forzosamente sin una protección adecuada, lo que implica, por ejemplo, el derecho a la protección contra "injerencias arbitrarias o ilegales" en el domicilio propio. La obligación del Estado de garantizar el respeto de ese derecho debe efectuarse respetando los principios de razonabilidad y proporcionalidad, evitando que estas personas queden sin vivienda o expuestas a violaciones de derechos humanos. En esa medida, el Estado debe brindar alternativas para que se proporcione otra vivienda, reasentamiento o acceso a tierras productivas, de acuerdo con cada caso.

\subsection{Coherencia y complementariedad con otras normas de derechos humanos y de derecho internacional humanitario}

En la actualidad existe un consenso en torno a la idea de circularidad e interdependencia entre los regímenes democráticos y la vigencia de los derechos humanos, en el que se considera que los primeros son condición para el ejercicio de los segundos y, a su vez, que estos se encargan de fortalecer la estabilidad 
democrática. De igual forma los diferentes instrumentos de derechos humanos remarcan su carácter interdependiente e indivisible, lo que implica que los Estados deben establecer diferentes vías de satisfacción y justiciabilidad.

En ese sentido, los principios Pinheiro también incorporan una serie de prescripciones en las que se contempla que los Estados deben garantizar que todos los procedimientos, instituciones, mecanismos y marcos jurídicos relativos a la restitución de tierras sean compatibles con las disposiciones de los demás instrumentos de derechos humanos y de derecho humanitario, estableciendo, por ejemplo, el deber correlativo de las organizaciones internacionales en colaborar con los gobiernos en la elaboración de políticas y programas nacionales de restitución.

De igual forma se establece como obligatorio el principio de interpretar estas obligaciones en un sentido según el cual no se limiten, alteren o menoscaben de algún otro modo los derechos reconocidos en otras normas de derechos humanos.

Estas disposiciones explícitamente no solo reconocen la importancia de lograr una coherencia interna y externa entre las medidas de restitución, sino que posibilitan una comprensión amplia del concepto de justicia en el que se fundamentan, ya que esta puede incorporar mecanismos que tengan relación con el cumplimiento de los instrumentos de derechos humanos en general y persiguen objetivos de justicia material que no necesariamente se enmarcan dentro de los objetivos de justicia correctiva.

\section{ACCESO A LA PROPIEDAD RURAL Y JUSTICIA AGRARIA}

Precisamente en relación con la necesidad de integrar la regulación jurídica de la restitución de tierras con las demás normas de derechos humanos es relevante hacer una breve reflexión sobre la importancia de las obligaciones de los Estados en materia de acceso a la propiedad rural debido a su importancia en la construcción de un concepto articulado e integral de la restitución de tierras. Es así como de forma clara, por ejemplo, las directrices voluntarias sobre la gobernanza responsable de la tenencia de la tierra proferidas por Naciones Unidas y con el objetivo de garantizar la seguridad alimentaria nacional, ha integrado, a sus objetivos estratégicos obligaciones encaminadas a la reparación integral en contextos de conflicto.

Ahora bien, como lo anota Coronado (2010), la nueva ola de constituciones en América Latina desde finales de los años ochenta implica la transformación de los marcos legales sobre la regulación de las tierras, los cuales se han elaborado a partir de la convergencia de diversas tendencias y procesos heterogéneos tales como:
[...] las tradiciones conservadoras del derecho civil heredadas del período colonial; el impacto de las ideas liberales en los países de la región; la consolidación de actores sociales 
rurales con demandas y expectativas; las políticas de desarrollo; la emergencia de gobiernos progresistas con ideologías cercanas al socialismo; y, en las últimas décadas, los procesos de globalización, y presión del capital sobre la tierra y otros recursos naturales (Coronado, 2010, pp. 98-99).

Por tal razón, las normas que rigen la materia albergan diversas tensiones. Sin embargo, es un hecho notable que las constituciones actuales establecen conexiones importantes con los tratados de derechos humanos que impactan la configuración de estos nuevos marcos legales de acceso a la tierra. Así, por ejemplo, los marcos constitucionales abordan aspectos como la libertad, la igualdad, derechos sobre las tierras de comunidades indígenas, propiedad y alimentación. Este marco permite fundamentar procesos más democráticos. Si bien, en ninguno de ellos se obliga a los Estados a emprender reformas agrarias, sí establecen mecanismos importantes para que la ciudadanía adopte estrategias de exigibilidad de derechos sobre la tierra a partir de los cuales es posible enfrentar el problema de concentración de la propiedad, común a los países latinoamericanos desde la época colonial, y que adquiere nuevas dimensiones en la época actual del libre comercio, las presiones por la industria extractiva y la agricultura comercial y la extranjerización de las tierras (Coronado, 2010).

\subsection{Directrices voluntarias sobre la gobernanza de la tenencia frente a la restitución de tierras}

A partir del año 2012 el Comité de Seguridad Alimentaria Mundial (CFS) de la
Organización de las Naciones Unidas para la Alimentación y la Agricultura (FAO), ratificó las directrices voluntarias sobre la gobernanza responsable de la tenencia de la tierra. Este se constituye en el primer instrumento mundial exhaustivo sobre la materia que complementa otros instrumentos internacionales.

De acuerdo con la FAO, los objetivos de las directrices son: el logro de la seguridad alimentaria para todos; la realización progresiva del derecho a una alimentación adecuada, a la vez que se respaldan los esfuerzos encaminados a la erradicación del hambre y la pobreza, así como la consecución de medios de vida sostenibles, la estabilidad social, la seguridad de la vivienda, el desarrollo rural, la protección medioambiental y al desarrollo social y económico sostenible (Organización de las Naciones Unidas para la Alimentación y la Agricultura-FAO-, 2012).

Las directrices son un texto de referencia en el que se estipulan principios y normas internacionalmente aceptados para las prácticas responsables de la gobernanza de la tenencia, lo que las convierte en un marco que los Estados pueden utilizar a la hora de elaborar sus propias estrategias, políticas, normas y programas (Palmer, Mika-Petteri, Munro-Faure, \& Arial, 2012).

Lo llamativo de este instrumento es que, dentro de las prescripciones que establece para el logro de objetivos de justicia social, incorpora una serie de medidas que guardan relación directa con la restitución de tierras, lo que implica un intento de articulación entre 
los procesos de reparación integral y la política de desarrollo rural del Estado, bajo el entendido de que ambas resultan importantes para la realización efectiva de los derechos humanos de la población campesina, indígena, afrodescendiente y de las víctimas de la violencia.

Entre las diferentes obligaciones contempladas en este instrumento frente a la restitución de tierras se señalan de forma principal las contempladas en los numerales $14.1,14.2,14.3$ y 14.4, tales como: i) las que consagran el deber de los Estados de adoptar mecanismos de reparación frente a hechos que impliquen la pérdida de los derechos legítimos de tenencia de la tierra, la pesca y los bosques; ii) las que prescriben la adopción de mecanismos de devolución de las tierras originales a quienes han sufrido su pérdida o a sus herederos, por resolución de las autoridades competentes, así como las que iii) establecen la adopción de una compensación rápida y justa en forma de dinero y/o parcelas o propiedades alternativas, asegurando un tratamiento equitativo de todas las personas perjudicadas cuando la devolución material no sea posible, y iv) las que ordenan la resolución efectiva de las inquietudes de las comunidades indígenas con arreglo al derecho nacional respecto de estas situaciones.

\section{CONCLUSIONES}

De acuerdo con el análisis efectuado, es posible identificar importantes puntos de encuentro entre la restitución de tierras y los objetivos de la justicia social agraria, lo que evidencia la configuración de un marco de protección que articula, a su vez, los mecanismos para la consecución de los objetivos de la justicia correctiva con los de la justicia redistributiva. Este marco tiene la potencialidad de buscar una solución duradera a los retos y a las tensiones que se derivan de implementar estos mecanismos de reparación en medio del conflicto, en contextos en los que persisten las causas estructurales que lo originaron.

Desde los trabajos reseñados en este artículo, que reflexionan sobre esta posible proximidad, se sostiene que dicha articulación es necesaria y deseable; sin embargo, las estrategias y los medios encaminados a tal fin deben lograrse a partir de la armonización de algunas tensiones, como, por ejemplo, las que se presentan entre la búsqueda de la eficiencia económica y la necesidad de obtener recursos adecuados y suficientes para adelantar la restitución de las tierras. Como alternativas se plantean, por ejemplo, la instauración de políticas redistributivas basadas en el fortalecimiento de la pequeña propiedad campesina que contribuyan a un modelo económico eficiente que, a su vez, redunden en mejores recursos para las reparaciones. También se sostiene que los programas de restitución deben integrarse adecuadamente con políticas de democratización y redistribución de la tierra y entablar mecanismos para que el Estado a través de una acción estratégica y efectiva fortalezca los recursos destinados tanto a la restitución como al desarrollo del campo. 
En el presente artículo aún no se presenta un planteamiento acabado que dé cuenta del fundamento teórico, práctico y empírico de esta articulación; sin embargo, al indagar en el concepto de justicia transicional y en las características fundamentales de este concepto, fue posible identificar algunos principios desde los cuales es posible justificar y desarrollar mecanismos dirigidos a este fin. En últimas, la justicia transicional permite delimitar el marco de acción del Estado en situaciones excepcionales en las que las sociedades se encuentran en una transición política.

La restitución de tierras, al ser un mecanismo de justicia transicional, también se encuentra definida y delimitada por este marco de justicia transicional, y en esa medida sus posibilidades y alcance tienen sentido, siempre y cuando se circunscriban a sus principios.

De la indagación aquí efectuada, fue posible corroborar que la justicia transicional involucra en su concepción un par de fines que en un comienzo abarcan tanto a los objetivos de justicia correctiva como los de justicia social o redistributiva, en la medida en que establece una serie de parámetros para lograr un adecuado balance entre ponerle fin al conflicto y prevenir la vuelta a la violencia, por una parte, y por otra, consolidar la paz mediante reformas estructurales y políticas incluyentes, lo que implica que los mecanismos adoptados para tal fin incluyen medidas restaurativas y de reparación, así como otras que se orienten a evitar la repetición de las condiciones sociales, políticas y econó- micas que ocasionaron el conflicto o que, de no corregirse, podrían hacer vanos los esfuerzos para la consecución de la paz, en la medida en que esta no sería estable y estaría constantemente amenazada.

Si bien es cierto que la consecución de estos objetivos es una tarea ardua y que solo es posible a partir de la adopción de mecanismos que resulten de los acuerdos políticos en cada sociedad particular en el marco de las posibilidades existentes (por tal razón el legislador goza de un importante margen de discrecionalidad para definir estos mecanismos en la ley), su identificación permite fundamentar alternativas en las que específicamente se involucre a la reflexión sobre la restitución de tierras, la importancia de integrar a ella objetivos de justicia social que se relacionen con aspectos como el acceso a la propiedad de los campesinos, o su reconocimiento como actores sociales imprescindibles en los procesos de democratización de las políticas agrarias.

En ese sentido bajo este entendido sería razonable incluso plantear que en buena medida el éxito de las políticas redistributivas o el desarrollo de la economía campesina, en últimas, también son objetivos de la restitución de tierras. Precisamente, la inclusión de deberes del Estado en materia de restitución de la tierra a los campesinos y a las comunidades que han sido privadas de ella con ocasión del conflicto armado, en las directrices voluntarias sobre la gobernanza de la tierra, en buena, medida demuestra que la consecución de objetivos como 
la erradicación del hambre y la pobreza, así como la consecución de medios de vida sostenibles, y el desarrollo rural se encuentran estrechamente ligados a la efectividad de las medidas de reparación integral y específicamente a la restitución de tierras, confirmando de esta forma que existe una serie de interdependencia entre los objetivos de justicia correctiva y los de justicia social.

Por otra parte, el logro de la reconciliación, como uno de los presupuestos de la justicia transicional, implica esfuerzos para evitar la división social y la conflictividad, así como, en últimas, el fortalecimiento de la democracia, lo que acentúa otro de los rasgos de esta relación de interdependencia, principio medular de la concepción de derechos humanos integrales que consagran diferentes instrumentos internacionales y bajo el cual se establece, como un principio hermenéutico imperativo, interpretar las prescripciones de dichas normas en un sentido según el cual estos no limiten, alteren o menoscaben de algún modo los derechos reconocidos en los demás instrumentos de derechos humanos.

Por último en el desarrollo y regulación de la restitución de tierras de conformidad con los Principios de Restitución de las Naciones Unidas, o más conocidos como Principios Phineiro, se señalaron algunos aspectos que desarrollan el sentido y alcance de la restitución de tierras, respecto de su articulación con los objetivos de justicia social. Por ejemplo el hecho de que esta se considere como un aporte significativo en el logro de una paz sos- tenible que promueva el desarrollo social y económico y que se comprenda como indispensable para la consecución de soluciones duraderas que permitan a las víctimas superar la pobreza y la dependencia como consecuencia de los hechos victimizantes, así como el cumplimiento efectivo del derecho a la restitución.

De igual forma se contempla la necesidad de respetar y garantizar los derechos de los segundos ocupantes en los programas de restitución, así como favorecer escenarios de reconciliación en consonancia con los objetivos de lograr una paz duradera y sostenible, en especial cuando esos terceros y ocupantes se encuentran en una situación de vulnerabilidad.

Este primer acercamiento al tema desde el análisis de los instrumentos internacionales propuestos será útil para profundizar en reflexiones posteriores donde se analice una situación particular y concreta, en la que no solo se describan los presupuestos normativos de los programas de restitución en el marco de experiencias transicionales, sino que se contextualicen en el marco de las dinámicas y las complejidades que estas implican frente a su implementación, en escenarios en los que las deudas sociales siguen alimentando el conflicto.

\section{REFERENCIAS BIBLIOGRÁFICAS}

Bergsmo, M. (2012). Introducción. En M. Bergsmo, C. Rodriguez, P. Kalmanovitz , E M. Saffon, (Eds.). Justicia distributiva en sociedades en transición (pp. 1-12). Oslo: Torkel Opsahl Academic EPublisher. 
Berry, A. (2010). La economía de la reforma agraria y las pequeñas granjas en los países en desarrollo: consecuencias para las situaciones de postconflicto. En M. Bergsmo, C. Rodríguez, \& P. Kalmanovitz, (Eds.). Justicia distributiva en tiempos de transición (pp. 25-76). Oslo: Torkel Opsahl Academic EPublisher.

Coronado, S. ( 2010). Marcos legales para el acceso a la tierra en América Latina: una mirada comparativa en ocho países de la región. Revista el Otro derecho, (No. 42), El sistema agroalimentario: Mercantilización, luchas y resistencias, pp. 97-128.

Corte Constitucional de Colombia. (2006). Sentencia C-370 de 2006. Colombia.

Corte Constitucional de Colombia. (2008). Sentencia C-1199 de 2008. Colombia.

Corte Constitucional de Colombia. (2012A). Sentencia C-052 de 2012. Colombia.

Corte Constitucional de Colombia. (2012B). Sentencia C-715 de 2013. Colombia.

Corte Constitucional de Colombia. (2013). Sentencia C-579 de 2013. Colombia.

Elster, J. (2012). Tierra, justicia y paz. En M. Bergsmo, C. Rodríguez \& P. Kalmanovitz, (Eds.). Distributive Justice in Transitions. (pág. 15-24). Oslo: Torkel Opsahl Publisher, International Peace Research Institute,.

Kalmanovitz, P. (2010). Justicia correctiva vs. Justicia social en casos de conflicto armado. Revista Estudios Socio-Jurídicos, (No.12), pp. 5985, Universidad del Rosario.

Oficina del Alto Comisionado de las Naciones Unidas para los Derechos Humanos. (1991). CESCR Observación general $\mathrm{N}^{\circ} 4$. ONU.

Oficina del Alto Comisionado de Naciones Unidas para los Derechos Humanos. (1999). Aplicación del Pacto Internacional de los Derechos Económicos, Sociales y Culturales, Observación general 7, El derecho a una vivienda adecuada (párrafo 1 del artículo 11 del Pacto): los desalojos forzosos (160 período de sesiones, 1997). ONU

Oficina del Alto Comisionado para los Derechos Humanos. (2007). Oficina del Alto Comisionado para los Derechos Humanos, Manual sobre la Restitución de las Viviendas y el Patrimonio de Refugiados y Personas Desplazadas. Aplicación de los "Principios Pinheiro". Washington.

Organización de las Naciones Unidas. (2004). El Estado de Derecho y la justicia transicional en sociedades en conflicto y post-conflicto:Informe del Secretario General.

Organización de las Naciones Unidas. (2007). Naciones Unidas, Handbook on Housing and Property Restitution for Refugees and Displaced Persons. Washington.

Organización de las Naciones Unidas para la Alimentación y la Agricultura. (2012). Directrices voluntarias sobre la tenencia de la tierra, la pesca y los bosques en el contexto de la seguridad alimentaria nacional. Roma.

Palmer, D., Mika-Petteri, T., Munro-Faure, P., E Arial, A. (2012). Promoción de un nuevo consenso mundial. Las Directrices voluntarias sobre la gobernanza de la tenencia. Revista sobre tenencia de la tierra, Volumen 1, (Número 1), pp. 19-36.

Phineiro, S. (2003). Naciones Unidas (2003). Relator Especial, Sr. Sergio Paulo Pinheiro. Derechos económicos, Informe Preliminar Restitución de viviendas $y$ de patrimonio con motivo del regreso de los refugiados y desplazados internos. Washington.

Proyecto protección de Tierras y patrimonio de la población desplazada. (2008). Notas sobre el derecho a la restitución y experiencias internacionales de restitución de bienes. Bogotá.

Sanchez, N., E Ibañez, C. (2014). La justicia transicional como categoría constitucional. En Ambos Kai [et. Al],. Justicia de transición y constitución: análisis a la sentencia C-579 de 
2013 de la Corte Constitucional (pp. 107-149). Bogotá: Temis.

Uprimny-Yepes, R., E Sánchez, N. (2010). Los dilemas de la restitución de tierras en Colombia. Revista Estudios Socio-Jurídicos, Volumen 12, (No. 2), pp. 305-342, Universidad del Rosario.
Williams, R. (2008). El derecho contemporáneo a la restitución de propiedades dentro del contexto de la justica transicional. En C. Diaz (Ed.). Reparaciones para las víctimas de la violencia política estudios de caso y análisis comparado (pp. 389-442). Bogotá: Centro Internacional para la Justicia Transicional. 
